\section{Squeezing a squishy object effectively controls pain in children during intravenous catheter insertion}

\author{
Grace Yuliona Sirtin Tumakaka,1,2 \\ Nani Nurhaeni, ${ }^{1}$ Dessie Wanda ${ }^{1}$ \\ 1 Faculty of Nursing, Universitas \\ Indonesia; ${ }^{2}$ Nursing Department, Prof \\ DR. R. D. Kandou Hospital, Indonesia
}

\begin{abstract}
This study aimed to identify the effect of distraction technique involving squeezing a squishy object on pain in children during intravenous catheter insertion. In this work, the control group posttest-only quasiexperimental design was used. This study involved 50 participants aged 3-15 years and was assigned into either intervention or control group. The intervention group was provided with a squishy object to squeeze as a form of distraction during intravenous catheter insertion, whereas the control group received the standard intervention. The pain was measured by using the WongBaker Faces Scale for 3-8 years old and the Visual Analog Scale or Numeric Rating Scale for children older than 8 years. Mann-Whitney analysis reveals significant difference in pain level between the intervention and control groups $(\mathrm{P}<0,001$; $\alpha=0.05$ ). The distraction technique involving squeezing a squishy object effectively reduced pain in children during intravenous catheter insertion and is recommended for pain management in nursing care in the pediatric ward.
\end{abstract}

\section{Introduction}

Intravenous cannulation is widely regarded as the most intimidating and painful medical procedure among hospitalized children. Moreover, the invasive procedure often results in pain and anxiety in both children and parents. ${ }^{1}$ A study has shown that intravenous cannulation is the most common source of pain in children, and they may remember it as the most painful procedure they have ever experienced. ${ }^{2}$ More than half $(65 \%)$ children who involved in a study related to experiences in intravenoues cannulation informs that they experiencing unbearable pain. ${ }^{3}$ Neglecting and delaying pain management during the invasive procedure may significantly affect a child's physical and psychological health, including increase in oxy- gen demand and alteration of blood glucose metabolism. 4

The most imperative quality of nursing care for patients in all conditions is indicated by pain management. ${ }^{5} \mathrm{~A}$ study has shown that effective pain and anxiety management should be taken into consideration before performing any invasive procedure in children, because a poorly managed pain experience may intensify the pain and anxiety experienced by these children in a subsequent invasive procedure. ${ }^{6}$

Distraction is one method that aims to reduce pain by directing a child's focus toward another object, which diverts his or her attention from the pain. Distraction is recognized as an effective acute pain management strategy in children during painful procedures. ${ }^{7}$ Studies have shown that distraction can reduce pain in children during a painful procedure. -12 $^{-12}$ Thus, the present study on the distraction technique involving squeezing a squishy object to control a child's pain undergoing intravenous catheter insertion is necessary.

\section{Materials and Methods}

This study employed the control group posttest-only quasi-experimental design. Total sampling technique was used to select the participants. The intervention group consisted of 23 children, whereas 27 children were included in the control group. The inclusion criteria were as follows: children aged 3-15 years who were about to undergo intravenous catheter insertion, who were compos mentis, and who were able to communicate. Children who experience severe pain due to medical conditions were excluded. This study was conducted for around 10 weeks from January to April in 2019 at the pediatric ward of the top referral hospital in Jakarta, Indonesia.

Demographic data, namely, age and gender, were collected. During the intravenous catheter insertion procedure, the children in the intervention group were asked to squeeze a squishy object, which is a ball approximately $6 \mathrm{~cm}$ in diameter. By contrast, the control group received a standard intervention. Shortly after the procedure, each child was asked to evaluate the pain they felt during the procedure by using the Wong-Baker Faces Scale for children 38 years old and the Visual Analog Scale or Numeric Rating Scale for children older than 8 years. Pain data were collected from all of the children after the first try. Data collection was performed after the researchers have explained the procedure and after they have obtained informed consent from each child's family. In the inter-
Correspondence: Nani Nurhaeni, Pediatric Nursing Department, Faculty of Nursing, Universitas Indonesia, Jalan Prof. Dr. Bahder Djohan, Kampus UI Depok, West Java, 16424 Indonesia.

Tel.: +6221.78849120 - Fax: +6221.7864124.

E-mail: nani-n@ui.ac.id

Key words: Distraction; intravenous insertion; pain

Acknowledgments: The researchers would like to express their gratitude to all participants and to all parties who facilitated this study.

Funding: This study was supported by Hibah PITTA B 2019, funded by DRPM Universitas Indonesia (No. NKB-0496/UN2.R3.1/HKP.05. 00/2019).

Contributions: GYST designed of the study, collected data, analysis data, searched the literature, and drafted the manuscript. $\mathrm{NN}$ has designed the study, critically reviewed the manuscript, and helped analysis reported in this manuscript. DW has designed the study, critically reviewed the manuscript, helped analysis reported, and manuscript preparation.

Ethical approval: The implementation of this evidence-based practice received ethical approval from the Research Ethics Committee of the Faculty of Nursing, Universitas Indonesia (No. 14/UN2.F12.D/HKP.02.04/2019).

Conflict of interest: The authors have no conflict of interest.

This work is licensed under a Creative Commons Attribution NonCommercial 4.0 License (CC BY-NC 4.0).

(C) Copyright: the Author(s), 2020

Licensee PAGEPress, Italy

Pediatric Reports 2020; 12(s1):8692

doi:10.4081/pr.2020.8692

vention group, intervention was conducted on Monday, Tuesday, and Wednesday, whereas in the control group, intervention was conducted on Thursday, Friday, and Saturday. This schedule was decided in order to balance the number of respondents in intervention and control group. This study was approved by the Ethics Committee of the Faculty of Nursing at Universitas Indonesia (No.14/UN2.F12.D/ HKP.02.04/2019).

The data collected were analyzed using SPSS. A homogeneity test showed that gender and age were homogeneous in both the intervention and control groups. Univariate and bivariate analyses were performed to analyze the data. In particular, univariate analysis was used to analyze the partici- 
pant's demographic characteristics, namely, age and gender. Bivariate analysis was employed to identify the impact of distraction technique, which involves squeezing a squishy object, on pain in children during intravenous catheter insertion.

\section{Results}

Table 1 shows that majority of the participants in the intervention group were females $(69.9 \%)$, whereas the control group was dominated by males $(59.3 \%)$. Table 2 shows that the median ages in the intervention and control groups were 7 and 8 years, respectively. The youngest age in both groups is three years. The Mann-Whitney test results on pain scale variable (Table 3) reveals a P-value of $<0.001$, implying a significant difference in pain score between the intervention group and the control group.

\section{Discussion}

Majority of the participants in the intervention group were females. Gender may play a role in the perception of pain in children; however, most studies were conducted on adults. ${ }^{13}$ Boys and girls differ in terms of perceiving, expressing, and controlling pain as well as in responding toward medication. These differences are affected by multiple factors, including family and cultural factors. A number of cultures respond to pain reticently, whereas other cultures respond to it out loud. Parental presence also plays a fundamental role in developing a child's ability to control pain. ${ }^{14}$

The median ages of the participants in the intervention and control groups were 7 and 8 years, respectively; this age bracket consists of school-age children. A child's capability to conceptualize pain is associated with cognitive development. The pain responses of pre-school children include being quiet, self-withdrawal, or hiding the pain. They may express the pain they perceived with the help of media or tools to describe the pain level that they experience. Moreover, pre-school children may assume the pain as punishment for misbehaving or for committing mischief. Their behavioral responses toward pain include refusal and crying. ${ }^{14}$ By contrast, children aged 8-12 years can remember personal events and associate their minds and feelings like adults do, but they cannot yet reason out. ${ }^{15}$ School-age children are able to communicate the type, location, and level of pain they perceive. Their behavioral responses toward pain include clenching their fist, touching a part of their body, shutting their eyes, and gritting their teeth. ${ }^{14}$ Thus, it can be concluded that a child's behavior toward pain becomes more adaptive with advancing age and intellectual maturity.

The statistical analysis result shows that the pain score of the participants in the intervention group was $0-6$; that is, the pain ranges from none to moderate. By contrast, the participants in the control group reported a pain score 4-10, indicating that the pain ranges from moderate to severe. The disparity in the result for the two groups is attributed to the implementation of distraction technique involving squeezing a squishy object in the intervention group to control pain during intravenous catheterization. This result indicates that the distraction technique involving squeezing a squishy object effectively reduced pain in children compared with standard intervention, which only involved deep breathing techniques.

When appropriately applied, a distraction effectively reduces pain during a painful procedure. ${ }^{16}$ Several studies involving school-age children have reported that distraction technique effectively reduces pain during intravenous cannulation. 11,17-21 Distraction is a technique used to divert a child's attention from painful stimuli throughout an invasive procedure. ${ }^{22}$ The present result supports the gate control theory, which states that nerve fibers that transmit sharp pain conjoin the dorsal horn as the final general pathway consisting of ther-

Table 1. Distribution of participants based on gender $(n=50)$.

\begin{tabular}{lcccc} 
Variable & \multicolumn{2}{c}{$\begin{array}{c}\text { Intervention } \\
(n=23)\end{array}$} & Control \\
& F & $\%$ & F & $\%$ \\
Gender & & & & \\
Male & 7 & 30.4 & 16 & 59.3 \\
Female & 16 & 69.9 & 11 & 40.7 \\
\hline
\end{tabular}

Table 2. Distribution of participants based on age $(n=50)$.

\begin{tabular}{lcc} 
Age & Median & Minimum-Maximum \\
Intervention Group & 7 & $3-15$ \\
Control Group & 8 & $3-14$ \\
\hline
\end{tabular}

Table 3. The difference in pain scale between the intervention and control groups $(n=50)$.

\begin{tabular}{lcccc} 
Variable & $\mathbb{N}$ & Median & Min-Max & P-value \\
Pain scale & & & & \\
Intervention group & 23 & 2 & $0-6$ & $<0.001^{*}$ \\
\hline Control group & 27 & 6 & $4-10$ & \\
\hline
\end{tabular}

*Significant at $\alpha<0.05$. mosensors and mechanoreceptors. Stimulation of a mechanoreceptor would close the gate of pain receptors through presynaptic inhibition, which prevents the perception of pain. ${ }^{23,24}$ When pain stimulus (intravenous catheterization) is received, als across nerve fibers will activate the eciceptors, and stimuli are convertopen the cell's gate, allowing the brain to receive pain messages; the $\mathrm{C}$ fiber nociceptors are inhibited by the distraction involving squeezing a squishy object. Mechanoreceptor stimulation closes the ed gate and inhibits the pain stimuli to lation is not perceived. The decreasing pain score in the intervention group shows that squeezing a squishy object would divert a child's attention from the pain stimuli, reducing his/her capacity to perceive pain. ${ }^{25}$ This result is supported by a previous study, which reported that distraction olving squeezing a soft ball reduces pain 4-6-year-old children who underwent result is consint wherein, compared with the pain level in the control group, the pain in the group subjected to such distractions as squeezing a soft ball, inflating a balloon, and playing distraction cards was lower; no significant eral nerves towards the dorsal horn and 
difference in pain was observed among the three types of distractions. ${ }^{11}$ Another study supporting the present result involved 7-12year-old children who underwent venipuncture procedure; the result suggests that the control group had a higher pain level than the group provided with kaleidoscope. ${ }^{19}$ Similarly, a random control trial (RCT) study that applied distraction technique involving inflating a balloon and cough trick in children aged 9-12 years during venipuncture revealed that the distraction techniques effectively reduced pain. ${ }^{20}$ This finding is consistent with that of a study conducted on 57 pre-school children who were subjected to a distraction involving blowing bubbles during venipuncture; the study reported lower pain levels in these children during the procedure. 10

There is a strong evidence showing that the distraction technique effectively reduces pain perceived by children during a needle insertion procedure. ${ }^{11}$ A study comparing the impact of deep breathing technique and music therapy on pain associated with intravenous cannulation in school-age children during blood transfusion suggests that both methods could significantly reduce pain in children, although music therapy was more effective than deep breathing techniques. ${ }^{18,20}$ In addition, an RCT study comparing the effect of deep breathing technique and blowing pinwheels in 6-12-yearold children who underwent intravenous catheterization reported that deep breathing technique and blowing pinwheels resulted in lower pain intensity than deep breathing technique. ${ }^{17}$

\section{Conclusions}

The distraction technique involving squeezing a squishy object effectively reduced pain in children during intravenous catheter insertion. This distraction technique can be easily implemented in nursing service specifically to reduce pain. Therefore, squeezing a squishy object is a recommended distraction in pediatric wards.

\section{References}

1. Baxter AL, Cohen LL, McElvery HL, et al. An integration of vibration and cold relieves venipuncture pain in a pediatric emergency department. Pediatr Emerg Care 2011;27:1151-6.
2. Friedrichsdorf SJ, Postier A, Eull D, et al. Pain outcomes in a US children's hospital: A prospective cross-sectional survey. Hosp Pediatr 2015;5:18-26.

3. Widyanti A, Agustini N. Gambaran prosedur pemasangan akses intravena yang dilakukan oleh perawat kepada balita: Pilot study. Jurnal Keperawatan Indonesia 2016;19:145-51.

4. Bowden VR, Greenberg CS. Children and their families: The continuum of care. 2nd Ed. Philadelphia: Lippincott Williams \& Wilkins; 2010.

5. Tomlinson D, von Baeyer CL, Stinson JN, Sung L. A systematic review of faces scales for the self-report of pain intensity in children. Pediatrics 2010;126:e1168-98.

6. Taddio A, Ipp M, Thivakaran S, et al. Survey of the prevalence of immunization non-compliance due to needle fears in children and adults. Vaccine 2012;30:4807-12.

7. Inan G, Inal S. The impact of 3 different distraction techniques on the pain and anxiety levels of children during venipuncture: A clinical trial. Clin J Pain 2019;35:140-7.

8. Kuo HC, Pan HH, Creedy DK, Tsao Y. Distraction-based interventions for children undergoing venipuncture procedures: A randomized controlled study. Clin Nurs Res 2018;27:467-82.

9. Canbulat N, Ayhan F, Inal S. Effectiveness of external cold and vibration for procedural pain relief during peripheral intravenous cannulation in pediatric patients. Pain Manag Nurs 2015;16:33-9.

10. Lilik LMP, Wanda D, Hayati H. The effectiveness of distraction (cartoonpatterned clothes and bubble-blowing) on pain and anxiety in preschool children during venipuncture in the emergency department. Compr Child Adolesc Nurs 2017;40:22-8.

11. Aydin D, Şahiner NC, Çiftçi EK. Comparison of the effectiveness of three different methods in decreasing pain during venipuncture in children: ball squeezing, balloon inflating and distraction cards. J Clin Nurs 2016;25:2328-35.

12. Sadeghi T, Shamshiri M, Mohammadi N, Shoghi M. Effect of distraction on children's behavioral responses to pain during IV catheter insertion. Journal of Hayat. 2013;18:1-9.

13. Tschugg A, Löscher WN, Hartmann S, et al. Gender influences radicular pain perception in patients with lumbar disc herniation. $J$ Womens Health 2015;24:771-6.

14. Kyle T, Carman S. Essential of pediatric nursing. 3rd ed. Philadelphia: Lippincott Williams \& Wilkins; 2017.

15. Pate J, Hush J, Hancock M, et al. A child's concept of pain: An international survey of pediatric pain experts. Children 2018;5:1-11.

16. Vakili R, Ajilian AM, Ghazizadeh HA, et al. Pain management in children with collaborative parents and healthcare team. Int J Pediatr 2015;3:561-73.

17. Abdolalizadeh H, Namdar AH, Janani $\mathrm{R}$, Arshadi BM. Comparing the effect of two methods of distraction on the pain intensity venipuncture in school-age children: A randomized clinical trial. Int J Pediatr 2018;6:8423-32.

18. Esmaeili K, Iranfar SH, Afkari B, Abbasi P. The comparison of the effect of music and rhythmic breathing techniques on pain severity of intravenous cannulation during blood transfusion. J Kermanshah Univ Med Sci 2008;12:129-39.

19. Karakaya A, Gözen D. The Effect of distraction on pain level felt by schoolage children during venipuncture procedure-randomized controlled trial. Pain Manag Nurs 2016;171:47-53.

20. Mutlu B, Balc1 S. Effects of balloon inflation and cough trick methods on easing pain in children during the drawing of venous blood samples: A randomized controlled trial. J Spec Pediatr Nurs 2015;20:178-86.

21. Valizadeh F, Shahabi M, Mehrabi, YE. A comparsion the two methods effect on divagatqn of mind: Music hay-ho rhythmic breathing techninqe. YAFTEH 2004;3:43-51.

22. Moadad N, Kozman K, Shahine R, et al. Distraction using the BUZZY for children during an IV insertion. J Pediatr Nurs 2016;31:64-72.

23. Hollins M, McDermott K, Harper D. How does vibration reduce pain? Perception 2014;43:70-84.

24. Melzack R, Wall PD. Pain mechanism: A new theory. Science 1965;150:971-9.

25. Koller D, Goldman RD. Distraction techniques for children undergoing procedures: A critical review of pediatric research. J Pediatr Nurs 2012;27: 652-81. 